\title{
A Question of Efficiency in Research
}

\section{This comment on the Rothschild and Dainton reports is by $\mathrm{Dr} M$. Gibbons and $\operatorname{Dr} R$. D. Johnston of the Department of Liberal Studies in Science, University of Manchester.}

THE stated objective of the Rothschild report is to provide a more efficient framework for the operation of government research and development. The means proposed for achieving this are summarily expressed in the governmentendorsed customer-contractor principle. This principle is based on a clear distinction between basic and applied research; basic research is by nature unplannable, and should be allowed to proceed according to the dynamics of science with a minimum of external control, whereas applied research, by definition, is directed towards a specific goal which should be established under a customer-contractor relationship. Dainton has questioned the possibility, and the wisdom, of such a sharp distinction, and the important area of strategic research, and the possibility of its subversion, has been the subject of much comment.

In spite of these difficulties, however, a more fundamental question to be examined in this context is whether the specific findings of research, be it basic or applied, are the only, or even the most important, contribution of the research worker. Recent studies of the role of science and technology in the process of technological innovation would suggest that this is not the case.

Science and technology can no longer be regarded as being linearly related in the sense that "science discovers, technology applies". Rather there is much evidence to support the view that scientific and technological activities are carried out by two distinct but related communities pursuing different ends and using different means, but that each community relies for its development on a complex matrix of interactions or mutual coupling. More specifically, coupling, in the form of interaction between the generators and users of information, is "person embodied" and is optimized by close, continuing, and pluralistic collaboration between the scientific and the technological communities.

The importance of effective coupling and its contribution to innovation have been emphasized by a number of studies in the USA, summarized by Price and Bass (Science, 164, 802; 1969) and by comparable studies of innovation in British industry by Dr J. Langrish and colleagues from the University of Manchester and Dr C. Freeman and Dr A. Robertson, of the University of Sussex. This has been highlighted by Freeman who has said that "access to recent fundamental research was of critical importance in nearly half of the process innovations studied. This sometimes took the form of working more closely with outstanding consultants, sometimes of recruiting outstanding scientists from academic life or immigrant scientists, sometimes of academic scientists themselves exploiting innovations, and sometimes simply of careful study of world scientific and technical journals".

The role of various types of coupling has been further demonstrated by an on-going study of the types of information used and the ways in which it was obtained by technologists in the resolution of technical problems that arose during the development in British industry of a wide range of new products characterized by their commonplace, unspectacular nature. In particular it has been shown that the major contribution from science was in the transfer, via a person-to-person contact, of information which was not being specifically sought, and which was frequently not from the research front.

Though most of these findings have been based on studies of the interaction of science and technology in the industrial sphere, there is no evidence to suggest that they are not applicable also to government departments. Indeed, much of the relevant research work in the USA has been in the context of research commissioned by government agencies or departments.

The results of these studies relevant to the current debate can be summarized as follows. First, the chief contribution of science to technology occurs in the transfer of a wide variety of information on the occasion of personal contact between the two communities. Second, the information transferred is rarely being specifically sought. Being by nature unplannable, attempts to optimize such transfers must concentrate on developing an environment favourable to coupling.

We do not suggest that the chief activity of the researcher should not be directed towards basic or applied research as needs require, or that the information obtained is not important as a contribution to the body of knowledge or in solution of a problem. The research cited above, however, does suggest that this is not the most important way in which the researcher contributes to the process.

It would seem, in the light of this evidence, that the implementation of the Rothschild recommendations may have at least two potentially adverse effects on the scientific community. First, the rigid application of the customer-contractor principle could serve to isolate scientists from technological problems as they attempt to define their areas of autonomy by retiring into basic research. Second, to use the scientists simply as a source of specific information for the solution of specific problems unnecessarily restricts the role they might play in contributing to the resolution of these and other problems, because it is clear from the studies cited above that the scientists' role in technical problem solving is by no means easily defined, even in general terms, from the outset and that more often than not they contribute in an unexpected way. In both these ways, the present proposals would have the effect, in our view, of reducing coupling and hence the efficiency which is their aim. At the same time, they include little which might promote an increase in this vital coupling.

Rothschild, in paragraph 21 , does stress the importance of dialogue, but with the limited purpose of selection of applied research targets. The need, however, is for a mechanism which allows for and encourages continuing dialogue between potential users such as the chief scientist, controller research and development, and their staff, and a wide range of the scientific community engaged in both basic and applied research. Changes in the organization of government research and development should have as a chief goal the expansion and augmentation of coupling so that the benefits of science can flow more readily to the entire community. 